\title{
BMJ Open Self-reported child abuse in the home: a cross-sectional survey of prevalence, perpetrator characteristics and correlates among public secondary school students in Kathmandu, Nepal
}

To cite: Neupane $D$,

Bhandari PM, Thapa K, et al. Self-reported child abuse in the home: a cross-sectional survey of prevalence, perpetrator characteristics and correlates among public secondary school students in Kathmandu, Nepal. BMJ Open 2018;8:e018922. doi:10.1136/ bmjopen-2017-018922

Received 30 July 2017 Revised 7 March 2018 Accepted 27 April 2018

Check for updates

Maharajgunj Medical Campus, Institute of Medicine, Tribhuvan University, Kathmandu, Nepal

Correspondence to

Dipika Neupane;

dipikaneupane28@gmail.com

Dipika Neupane, Parash Mani Bhandari, Kiran Thapa, Shristi Bhochhibhoya, Shristi Rijal, Ramjee Prasad Pathak

\section{ABSTRACT}

Objectives To explore the prevalence, perpetrator characteristics and the correlates of child abuse in Kathmandu, Nepal.

Methods For this cross-sectional study, we translated the internationally validated questionnaire developed by the International Society for Prevention of Child Abuse and Neglect, Child Abuse Screening Tool-Child Home into Nepali. We added questions on descriptive information about students and their family to the questionnaire. We recruited students from 20 schools selected randomly -2 from each of the 10 electoral constituencies of Kathmandu district. In each school, we administered the questionnaires to the students in a classroom selected randomly. To assess the correlates, we ran multilevel multivariable logistic regression models, stratified by schools.

Results Among the 962 students, $88.88 \%$ had experience of at least one form of abuse throughout their lifetime. Psychological abuse was the most prevalent form of abuse (previous year: $75.19 \%$; lifetime: $76.15 \%$ ) followed by physical abuse, exposure to violence, neglect and sexual abuse. Adults were the most common perpetrators of child abuse (37.55\%). The correlates identified in this study mostly aligned with the global literature on correlates of abuse. Female students were more likely to report neglect (previous year: adjusted OR (AOR) $1.50,95 \% \mathrm{Cl}$ 1.10 to 2.04; lifetime: $A O R \quad 1.49,95 \% \mathrm{Cl} 1.10$ to 2.02), but no gender difference was observed with other forms of abuse. Students living with a single parent had a greater likelihood of exposure to violence (previous year: AOR 2.55, $95 \% \mathrm{Cl} 1.31$ to 4.94 ; lifetime: $\mathrm{AOR} 2.77,95 \% \mathrm{Cl} 1.39$ to 5.53), neglect (previous year: $\mathrm{AOR} 2.01,95 \% \mathrm{Cl} 1.10$ to 3.69; lifetime: AOR $2.08,95 \% \mathrm{Cl} 1.14$ to 3.81 ) and sexual abuse (previous year: AOR 3.03, 95\% Cl 1.45 to 6.37 ; lifetime: AOR 2.49, 95\% Cl 1.21 to 5.14).

Conclusions 0 ver $88 \%$ of students reported experiencing child abuse in the home in one or more forms throughout their lifetime. Delineating the reasons for the high burden and its implications are important topics for future research.
Strengths and limitations of this study

- This study is the first to exhaustively explore all forms of child abuse in the home among schoolgoing children in Nepal using an internationally validated tool.

- The findings are based on a large sample of students recruited from 20 schools - 2 from each of the 10 electoral constituencies of Kathmandu district.

- As the results are based on students' self-reported history of abuse, recall bias and either under-reporting and/or over-reporting instances of abuse may exist.

\section{INTRODUCTION}

Child abuse comprises an act of violence, psychological abuse, neglect, physical abuse or sexual abuse perpetrated against children. Globally, a huge proportion of children self-report events of abuse, with prevalence rates of sexual abuse, physical abuse, emotional abuse, physical neglect and emotional neglect being $12.7 \%, 22.6 \%$, $36.3 \%, 16.3 \%$ and $18.4 \%$, respectively. ${ }^{1}$ The experience of abuse is linked with increased medical costs and several grave health consequences that can extend to adulthood including attachment disorders, behavioural disorders, depression, post-traumatic stress disorder, altered neurobiological anatomies, suicidal ideation, risky sexual practices and sexually transmitted infections. ${ }^{2-4}$

Though several studies have explored the burden of abuse in children and its ill-effects, prevalence studies are scant from low-income and middle-income countries. ${ }^{1}$ This gap in literature is particularly acute in Nepal where there are only a few studies on physical and sexual abuse in children, ${ }^{5-7}$ and no study to 
date has comprehensively explored all forms of child abuse in the home using a validated instrument. ${ }^{8}$

Research on perpetrators of child abuse in Nepal is also lacking. Abuse perpetrated by adults, especially physical abuse, is likely to be highly prevalent as corporal punishment 'to discipline' the children is common, and punitive actions against the adults perpetrating violence are rare in Nepal. ${ }^{9}$ Having information on the most common perpetrator characteristics could help in devising primary prevention measures to detect victims of child abuse more efficiently.

Studies have linked increased odds of perpetuating child abuse with lower family income. ${ }^{1011}$ Considering this knowledge gap in children from lower family incomes, we solely focused on this population in our study. Our objectives were to assess the prevalence of child abuse in the home, perpetrator characteristics and the correlates of abuse among public secondary school students in Kathmandu, Nepal.

\section{METHOD}

We carried out this cross-sectional study in Kathmandu in August 2015. Kathmandu is a central hill district in Nepal where the capital city of the country is located. As private schools are expensive to afford, children from low-income families in Nepal generally receive education from free-to-attend public schools. ${ }^{12}$ So, to enrol children from lower family incomes, we approached public schools only in this study.

With a margin of error of 0.05 , a confidence level of $95 \%$, a design effect of 2, a non-response of $20 \%$ and a population proportion of 0.5 (since the prevalence of abuse in Nepali students was unknown), we calculated a sample size of 961 . Assuming that at least 50 students will be present on the day of data collection in a class of 60 - the typical class size in Nepali schools - ${ }^{13}$ we decided to include 20 secondary schools, 2 schools from each of the 10 electoral constituencies of Kathmandu. From the District Education Office, we obtained a list of all 159 public secondary schools in the district, grouped them by their location and randomly selected two schools from each constituency. We used the schools' identifying codes to randomly select the schools via a lottery method. The principal investigator carried out the school-level sampling. After receiving permission from the school principal, one of the investigators who visited the school for data collection randomly selected a classroom from grade 8,9 or 10 via a lottery method. Then, we invited all students present in the classroom for participation in this study.

\section{Ethics}

While the need for parental consent was waived for this study, we obtained permission from the principal and the teachers of the school prior to data collection. Before distributing the questionnaires, we informed the students about the study objectives and oriented them on the correct method to complete the questionnaire. Each student provided written informed consent. We assured their right to choose to participate in the survey and to skip questions they were hesitant about. After collecting the data, we briefed the students about the global burden of child abuse. To make sure the students did not feel intimidated to share their experiences, we did not record any personal identifiers in the questionnaire. For this reason, we did not link the response collected with individual students and did not report the perpetrators to the authorities ourselves. However, at the end of the data collection, we informed the class about the emergency hotline toll-free number (ie, 1098) to report any cases of child abuse they would face or witness. Child Workers in Nepal Concerned Centre, a leading non-government organisation working on child rights in Nepal, in collaboration with the Government of Nepal and the Nepal Telecommunications Authority, manages this toll-free number.

\section{Participant involvement}

The research questions we explored in this study were guided by the observed gaps in the evidence on child abuse locally. We did not involve participants in designing the study, recruiting participants or conducting the study. We did not record personal identifiers for ethical reasons which made us unable to share our study results with the participants personally. However, the dissemination plan included sending a press release following the publication to share our study results among the general public, including the study participants.

\section{Measures}

The International Society for Prevention of Child Abuse and Neglect (ISPCAN) has developed a questionnaire to screen children for abuse in the home. We used this structured questionnaire, Child Abuse Screening ToolChild Home, in its entirety, to collect information from students. The Child Abuse Screening Tool-Child Home, a population-based survey tool, includes questions on all forms of childhood victimisation in the homes of children aged 11-18 years. It consists of 36 child abuse questions which are grouped into exposure to violence, psychological abuse, neglect, physical abuse and sexual abuse. Each item measures the frequency with which the student experienced the specific event of abuse. Response options to the questions are: 'many times', 'sometimes', 'never' and 'not in the past year but this has happened'. ${ }^{14}$

Ideally, the parental socioeconomic information extracted either through existing records or collected from the parents would be the most informative. Since the children were the only source of information in this study and it was doubtful if the secondary school students were informed enough to accurately report the parental socioeconomic factors, we gathered descriptive social information about the children's parents and their household environments, which included: alcohol use, tobacco 
use, living arrangements, family size and parental education, as a proxy of the parental socioeconomic conditions.

We recorded the students' age in years. During analysis, we categorised the information on the ethnicity of students into two groups: 'Brahmin/Chhetri' and 'Others'. Brahmin and Chhetri make up more than a fourth of the population and have been dominant in most of the fields and elite professions in Nepal. ${ }^{15}$ We considered this social dominance of certain castes in Nepal during the categorisation. We recorded the information on students' religion and categorised it into two groups before analysis: 'Hindu' and 'Others'. For the students' living arrangement, we grouped the information into 'live with both parents' if $\mathrm{s} /$ he lived with both father and mother, 'live with single parent' if $s /$ he lived with either father or the mother or 'do not live with parents' if s/he lived neither with father nor with the mother. We collected the information on the family size of students with the question: 'How many members do you have in your family?' We also collected information on the mother's age in years. Similarly, we grouped the responses about father's and mother's education into four categories: 'Illiterate', 'Primary', 'Secondary' and 'High school or above'. The questionnaire also asked students: 'Does anybody in your family drink alcohol?' and 'Does anybody in your family smoke?' to record information on alcohol and tobacco use, respectively, in the family. Students responded to these two questions either as 'Yes' or a 'No'.

Two of the investigators translated the original questionnaire, which is not validated in the Nepali setting yet, into Nepali and a third investigator back-translated it independently to ensure accuracy of the translation. Before initiating the survey, we pretested the tool among 30 students in a setting similar to the original study site. Based on the experiences from pretesting, we changed the wordings of some questions for clarity and suitability of response options.

\section{Data analysis}

We analysed the data in STATA V.13.0 and produced the figures in R using the lattice package. In the first step, we scored responses from the students based on the criteria provided by the developers of the Child Abuse Screening Tool-Child Home. ${ }^{14}$ If a student responded affirmatively to at least one of the items within a form of abuse, we considered it as a case of abuse for that particular form. Similarly, if a student reported having an experience of more than 1 item of abuse, out of the 36 items in the Child Abuse Screening Tool-Child Home, we considered it as a case of polyvictimisation. Then, we performed descriptive analyses to calculate the prevalence of individual forms of abuse and polyvictimisation, and their $95 \%$ CIs. We confirmed the linearity of the logit and the continuous predictors with Box-Tidwell test. To identify the correlates, we conducted multilevel multivariable logistic regression analysis using the melogit function in STATA with variables of students' and their family information at the first level and schools' identifying codes at the second level of the model. Each variable entered in the model was adjusted for all the other variables while computing the adjusted OR (AOR) and its 95\% CI. Missing values were excluded listwise while running the regression models. We considered a probability value of $<0.05$ for statistical significance where CIs for AOR were set at $95 \%$.

\section{RESULTS}

None of the students declined to participate in the study. From the response of 984 students who participated, we excluded 22 questionnaires in which responses for more than $10 \%$ of the questions were missing. Thus, the final data analysis included the response from 962 students.

Students' age ranged from 12 years to 18 years with an average of 15 years. Of the students, $79.5 \%$ belonged to the 14-16 years age group. The mean age of students' mothers was 39 years and the average family size was five. Detailed information on the descriptive characteristics of students and their family is presented in table 1 .

\section{Prevalence of child abuse}

The majority of students had experienced at least one form of abuse; $88.09 \%$ (95\% CI $85.79 \%$ to $90.06 \%$ ) of students had experienced at least one form of abuse in the previous year while $88.88 \%$ (95\% CI $86.63 \%$ to $90.78 \%$ ) of students had such experience throughout their lifetime. The majority of students reported polyvictimisation: $78.09 \%$ (95\% CI $75.25 \%$ to $80.69 \%$ ) reported polyvictimisation in the previous year while $78.99 \%$ (95\% CI $76.18 \%$ to $81.55 \%$ ) reported polyvictimisation over their lifetime. On average, students reported experiencing 6.27 victimisations throughout their lifetime and 5.79 victimisations in the previous year. The most prevalent form of abuse was psychological abuse (previous year: $75.19 \%, 95 \%$ CI $72.31 \%$ to $77.86 \%$; lifetime: $76.15 \%, 95 \%$ CI $73.31 \%$ to $78.79 \%$ ), followed by physical abuse, exposure to violence, neglect and sexual abuse. Table 2 presents detailed information on the previous year and lifetime prevalence of individual forms of child abuse among students.

\section{Perpetrator characteristics}

A similar pattern of perpetrators' age category was observed for all forms of abuse. Adults were the most common perpetrators. Overall, $37.55 \%$ of the reported events of abuse were perpetrated by adults while $7.33 \%$ of events were perpetrated by other children or adolescents (figure 1).

Students who had experienced sexual abuse were asked about their familiarity with the perpetrators. A very low percentage of perpetrators were well known to the students except for cases where a sex video was made, or the students were talked to in a sexual way. Overall, the distribution of students' familiarity to the perpetrators was non-uniform across different natures of sexual abuse (figure 2). 
Table 1 Descriptive characteristics

\begin{tabular}{|c|c|c|}
\hline Characteristics & Number & Percentage \\
\hline \multicolumn{3}{|l|}{ Age (years) } \\
\hline Mean (SD) & $15(1.20)$ & \\
\hline \multicolumn{3}{|l|}{ Gender } \\
\hline Female & 539 & 56 \\
\hline Male & 422 & 44 \\
\hline \multicolumn{3}{|l|}{ Ethnicity } \\
\hline Brahmin/Chhetri & 317 & 34 \\
\hline Others & 615 & 66 \\
\hline \multicolumn{3}{|l|}{ Religion } \\
\hline Hindu & 715 & 74 \\
\hline Others & 245 & 26 \\
\hline \multicolumn{3}{|l|}{ Living arrangement } \\
\hline Do not live with parents & 200 & 22 \\
\hline Live with single parent & 70 & 7 \\
\hline Live with both parents & 650 & 71 \\
\hline \multicolumn{3}{|l|}{ Family size (members) } \\
\hline Mean (SD) & $5(1.79)$ & \\
\hline \multicolumn{3}{|l|}{ Mother's age (years) } \\
\hline Mean (SD) & $39(6.31)$ & \\
\hline \multicolumn{3}{|l|}{ Mother's education } \\
\hline High school or above & 63 & 7 \\
\hline Secondary & 180 & 19 \\
\hline Primary & 260 & 27 \\
\hline Illiterate & 446 & 47 \\
\hline \multicolumn{3}{|l|}{ Father's education } \\
\hline High school or above & 118 & 13 \\
\hline Secondary & 300 & 32 \\
\hline Primary & 303 & 32 \\
\hline Illiterate & 215 & 23 \\
\hline \multicolumn{3}{|l|}{ Alcohol use in family } \\
\hline Someone uses & 392 & 41 \\
\hline No one uses & 557 & 59 \\
\hline \multicolumn{3}{|l|}{ Tobacco use in family } \\
\hline Someone uses & 483 & 51 \\
\hline No one uses & 464 & 49 \\
\hline
\end{tabular}

Numbers may not add up to 962 because of missing data.

\section{Correlates of child abuse}

The results from multilevel multivariable logistic regression analysis, as presented in table 3 , show that correlates for the lifetime and previous year's experience were mostly similar. The likelihood of exposure to violence was higher for older students (previous year: AOR 1.14, $95 \%$ CI 1.01 to 1.30 ), students living with a single parent (previous year: AOR 2.55, 95\% CI 1.31 to 4.94; lifetime: AOR 2.77, 95\% CI 1.39 to 5.53), students with older mothers (previous year: AOR 1.03, 95\% CI 1.00 to 1.05 ; lifetime: AOR 1.03, 95\% CI 1.00 to 1.05 ) and students who had a tobacco user in the family (previous year: AOR $1.78,95 \%$ CI 1.26 to 2.50 ; lifetime: AOR 1.78, 95\% CI 1.26 to 2.51). Being female (previous year: AOR $1.50,95 \%$ CI 1.10 to 2.04; lifetime: AOR 1.49, 95\% CI 1.10 to 2.02), not living with parents (previous year: AOR 1.74, 95\% CI 1.18 to 2.55; lifetime: AOR $1.70,95 \%$ CI 1.16 to 2.49 ) and living with a single parent (previous year: AOR 2.01, 95\% CI 1.10 to 3.69; lifetime: AOR 2.08, 95\% CI 1.14 to $3.81)$ were associated with higher odds of experiencing neglect.

Likewise, students whose father had completed at least high school (lifetime: AOR $1.98,95 \%$ CI 1.00 to 3.92 ) or secondary school (lifetime: AOR 1.68, 95\% CI 1.04 to 2.72) and who had a tobacco user in the family (previous year: AOR 2.01, 95\% CI 1.40 to 2.90; lifetime: AOR 2.10, $95 \%$ CI 1.45 to 3.05 ) were more likely to experience physical abuse. Similarly, a higher likelihood of reporting sexual abuse was observed for older students (previous year: AOR 1.44, 95\% CI 1.18 to 1.76; lifetime: AOR 1.41, $95 \%$ CI 1.17 to 1.70 ), students living with a single parent (previous year: AOR 3.03, 95\% CI 1.45 to 6.37; lifetime: AOR 2.49, 95\% CI 1.21 to 5.14) and students with larger families (previous year: AOR 1.12, 95\% CI 1.01 to 1.26).

\section{DISCUSSION}

To our knowledge, this is the first study to exhaustively assess the burden of all forms of child abuse in the home in Nepal. We found that the prevalence is high for all individual forms of abuse. Almost 9 out of 10 students had experienced at least one form of abuse during their lifetime and most students had experienced at least one form of abuse in the previous year. Overall, a majority of the abuse perpetrators were adults irrespective of the forms of abuse.

Growing up in a society where corporal punishment is common is challenging for children. This is reflected in the high prevalence of physical abuse in Kathmandu, a district where corporal punishment at home is socially acceptable and lawful. ${ }^{9}$ Furthermore, due to social acceptance of corporal punishment, abuse perpetrated by adults at home is less likely to be reported because of the perception that these practices are normal. This makes the events of abuse less likely to be reported and hence warrants the use of self-administered questionnaires with specially tailored questions to document these experiences.

In this study, psychological abuse was the most frequently reported form of abuse followed by physical abuse, exposure to violence, neglect and sexual abuse. Though less studied and rarely talked about openly, this study revealed that psychological abuse has the greatest burden in Kathmandu. Comparatively sexual abuse was the least reported form of abuse; however, the prevalence was still high. A meta-analysis reported a wide range in the prevalence estimates of child sexual abuse depending on how sexual abuse was defined with a pooled prevalence 
Table 2 Prevalence of child abuse

\begin{tabular}{lll}
\hline Form of abuse & Previous year & Lifetime \\
\hline Exposure to violence & $56.53(53.35$ to 59.65$)$ & $59.47(56.31$ to 62.56$)$ \\
\hline Psychological abuse & $75.19(72.31$ to 77.86$)$ & $76.15(73.31$ to 78.79$)$ \\
\hline Neglect & $45.41(42.25$ to 48.60$)$ & $46.25(43.09$ to 49.44$)$ \\
\hline Physical abuse & $65.43(62.34$ to 68.40$)$ & $67.34(64.27$ to 70.26$)$ \\
Sexual abuse & $11.26(9.40$ to 13.44$)$ & $12.74(10.76$ to 15.02$)$ \\
At least one form of abuse & $88.09(85.79$ to 90.06$)$ & $88.88(86.63$ to 90.78$)$ \\
\hline Polyvictimisation & $78.09(75.25$ to 80.69$)$ & $78.99(76.18$ to 81.55$)$ \\
\hline Mean number of victimisations (SD) & $5.79(5.21)$ & $6.27(5.57)$ \\
\hline
\end{tabular}

Data are percentage $(95 \% \mathrm{Cl})$ unless indicated otherwise.

Total count for individual form of abuse may not be 962 because of missing data.

of 'mixed sexual abuse' of $15 \%$ (95\% CI $9 \%$ to $24 \%$ ) for girls and $8 \%(95 \%$ CI $4 \%$ to $16 \%)$ for boys globally. ${ }^{16}$ Our estimates of both the previous year and the lifetime prevalence fall within this pooled estimate of $8 \%$ for boys and $15 \%$ for girls and are comparable to the median (12.5\%) of the prevalence rates pooled in this meta-analysis. Our finding on prevalence of sexual abuse is also of interest because it has remained a high priority area of research in Nepal and earlier studies from Nepal too focused on exploring its burden and complications. ${ }^{57}$

A high proportion of students reported multiple victimisations; on average, students reported more than five victimisations in the past year and more than six victimisations throughout their lifetime. Repeat victims are more likely to experience trauma; ${ }^{17}$ have trouble socialising with other people; develop post-traumatic stress disorder, depression and self-harm ideation; and live unhealthier lives. ${ }^{18} 19$

We observed that the likelihood of reporting exposure to violence and sexual abuse was higher for older students. This finding aligns with a previous study, ${ }^{20}$ and could be a result of increased risk exposure over time. Alternatively, older students may have an increased awareness about abusive behaviours and are subsequently more likely to report such abuses. In addition to the older students, we observed that students with older mothers had a higher likelihood of exposure to violence but no such association of mother's age was observed with other forms of abuse.

While we observed no gender difference with most forms of abuse, the frequency of neglect was significantly higher for girls. This disparity may be the result of the continued dominance of patriarchal attitudes and is also reflected in the practice of sex-selective abortions favouring male children. ${ }^{21}$ As cultural transformation in urban areas like Kathmandu is rapid, it is hard to state what proportion of the disparity observed in our study is attributable to these traditional views. Further research is needed to better understand the relationship between gender and child neglect in the context of Nepal.

In comparison to children living with both parents, children living with a single parent or those not living with parents reported feeling more neglected. Also, children

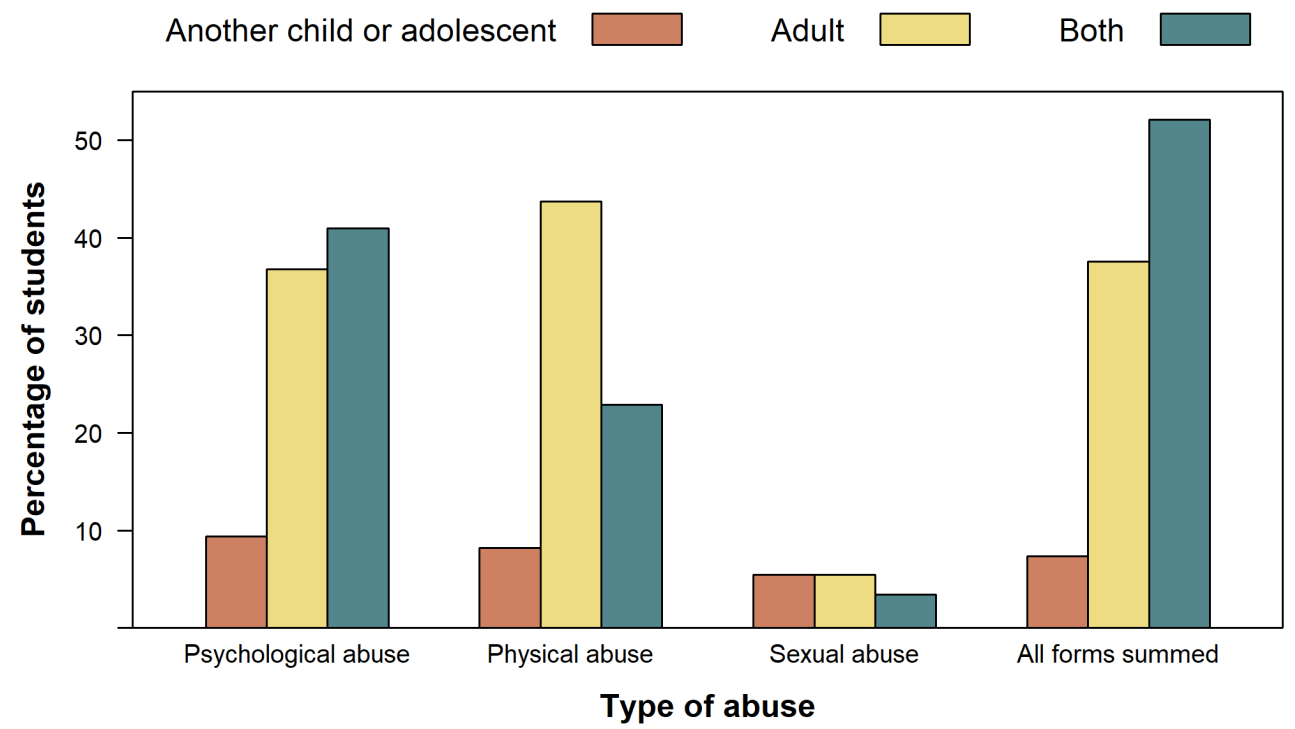

Figure 1 Types of child abuse and perpetrator's age category $(n=791)$. 
Very familiar $\square \quad$ Not very familiar $\square \quad$ Not familiar at all

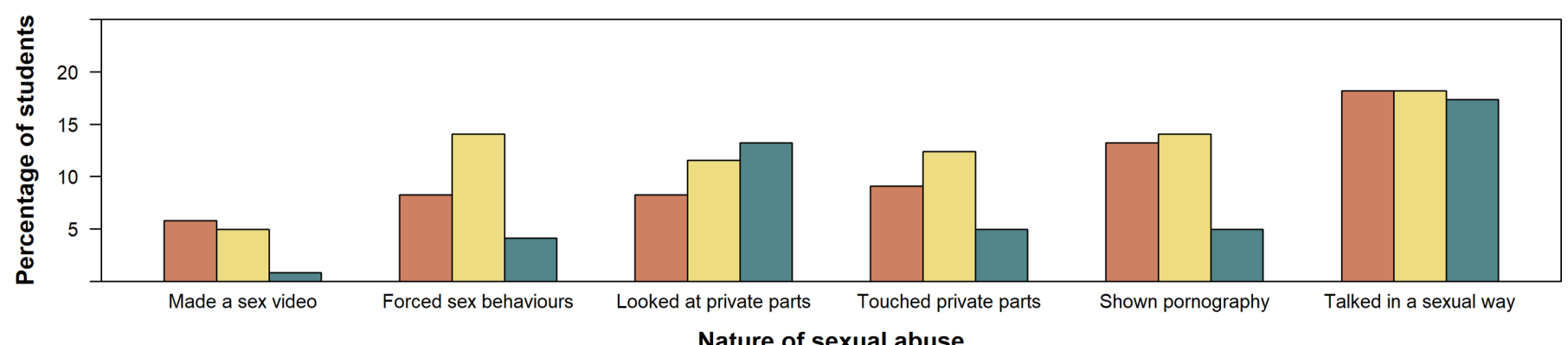

Nature of sexual abuse

Figure 2 Nature of sexual abuse and familiarity of the students to the perpetrator $(n=121)$.

living with a single parent reported significantly higher exposure to violence and sexual abuse in comparison to those living with both parents. These observations clearly underscore the important role of parents in protecting their child from abuse. Alternatively, it is also possible that children with both parents are less likely to report a history of experiencing abuse in comparison to those with a single or no parent. The actual mechanisms behind these associations of the living arrangement with experience of abuse remain a question for future research.

We also found that larger families were linked with a higher likelihood of children experiencing sexual abuse in the previous year. Previous studies have linked large family size with greater risk of child abuse. ${ }^{22} 23$ However, Emery and colleagues argue that it is not the family size, but the willingness of family members to act against child abuse on witnessing an event, that determines the likelihood of the child in the family experiencing abuse. ${ }^{24}$

We observed that students whose father had at least a secondary education had a higher likelihood of reporting physical abuse in comparison to the students whose fathers were illiterate. This finding does not align with the evidence on the relationship between paternal education and physical abuse. Other studies that have explored this relationship reported that higher parental educational attainment is linked with lower rates of physical abuse, ${ }^{25}$ with low maternal education attainment being a risk factor for physical abuse. ${ }^{11}$ In our study, we did not observe any relationship between maternal education and any forms of abuse.

Students with a tobacco user in the family were at higher risk of exposure to violence and physical abuse than students without a tobacco user in the family. Though tobacco use during pregnancy, and alcohol and other addictive substances use have all been linked with child abuse ${ }^{26}$ this is one of the first studies to report the cross-sectional association of current tobacco use with child abuse. Interestingly, alcohol use had no significant association with the experience of any form of child abuse in this study.

\section{Strengths and limitations}

This study has several strengths which add to the reliability of the findings. This study enrolled a large group of students using a predefined systematic technique recruiting students from two schools in each electoral constituency of Kathmandu. While previous studies in Nepal have focused only on sexual abuse, this is the first study to our knowledge to exhaustively explore all forms of child abuse in the home. Likewise, our use of internationally validated and commonly used tools to assess child abuse also helps with comparisons of our findings.

We also acknowledge that this study has a few limitations. Rather than using official records, we relied on the response of students recorded from the self-administered questionnaire for identifying events of child abuse. This is susceptible to recall bias and might be subjective to students' response. Given that child abuse is stigmatised in the community, chances of exaggerating or withholding information by students also exist. In this study, we enrolled students from public schools in Kathmandu, so any generalisation of these findings to other parts of Nepal and to those attending private schools should be approached with caution. Furthermore, we assessed the students' experience of abuse in the home only. So, a generalisation of these findings to child abuse in school or other institutional settings can be inaccurate.

The main limitation of this study, inherent in the study design, is that we enrolled children from schools only. The National Population and Housing Census 2011 reports that $16 \%$ of the population aged $12-18$ years in Kathmandu do not attend a school. ${ }^{27}$ Although children who drop out of school are more likely to experience abuse, ${ }^{28}$ empirical literature comparing child abuse prevalence between children who attend school and those who do not is scarce. This absence limits the generalisability of our findings to children who are left out of school. Similarly, another important point to note is that we carried out this survey four months after the Nepal earthquake of 25 April 2015. As natural disasters, including earthquakes, are associated with an increased risk of children experiencing abuse, ${ }^{29}$ it is not sure if the observed high prevalence of child abuse is linked with the earthquake. We recommend carrying out similar prevalence surveys in the future to explore if our study findings can be replicated. 


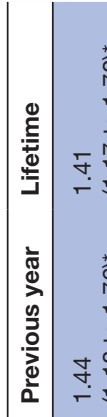

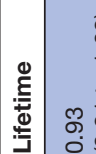

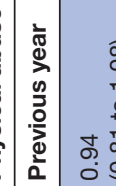

章

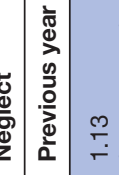

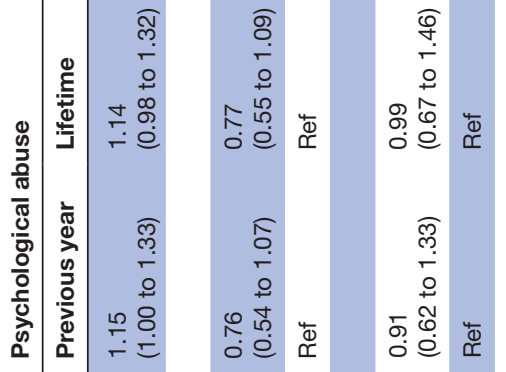

离

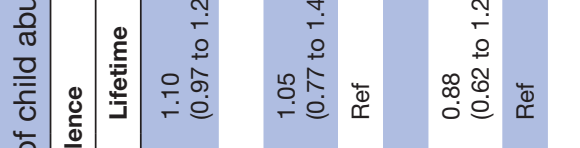

0
0
$\frac{0}{0}$
$\frac{0}{0}$
$\frac{0}{x}$
$\frac{0}{x}$
0
$\frac{0}{0}$
0
$\frac{0}{0}$
$\frac{\pi}{0}$
$\frac{0}{0}$
0
0
0
$\frac{0}{0}$
$\frac{10}{10}$

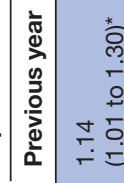
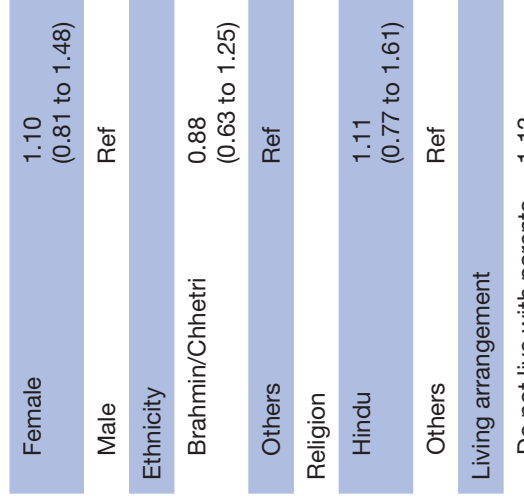

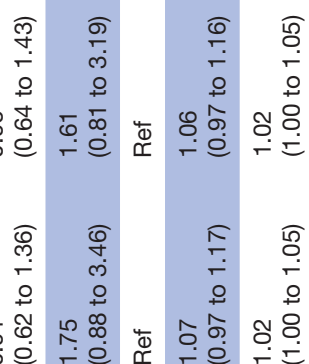

芯芯

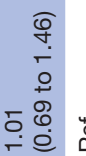

임

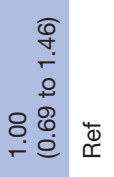

疍

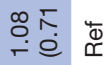

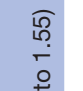

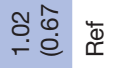

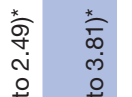

윰유

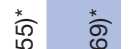

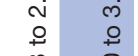

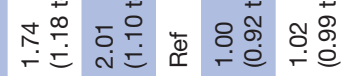

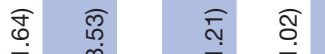

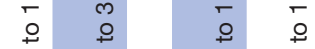

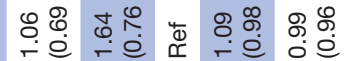

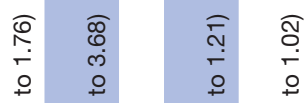

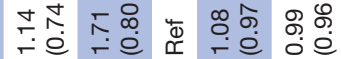

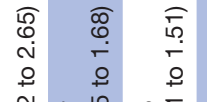

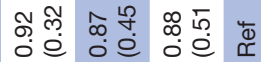

ㅎำ ส

용

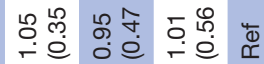

ल $\overline{0}$

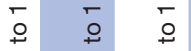

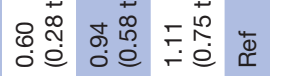

त़

ㅇ

ஜํํㅇ 융

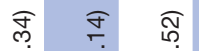

ᄃ 5

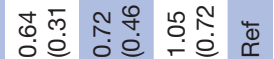

वे ळ

एक

๙ึ

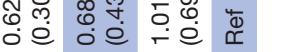

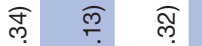

¿

赵胥

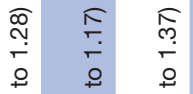

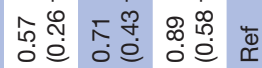

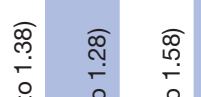

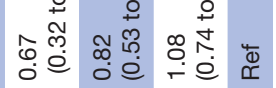

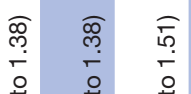

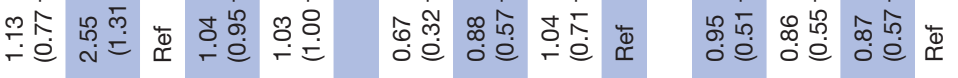

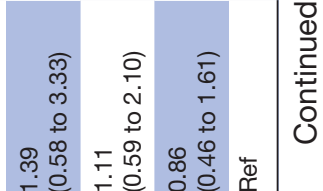

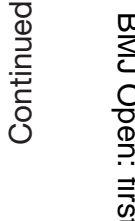

$\stackrel{\vec{F}}{\stackrel{0}{0}}$

$\frac{\overline{0}}{\frac{0}{\overline{0}}}$

兽

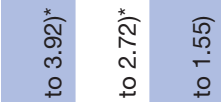

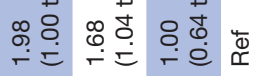

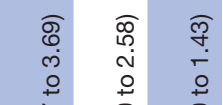

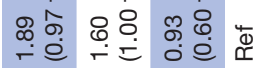

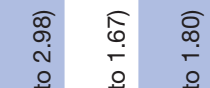

○®

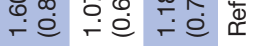

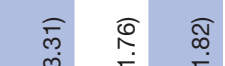

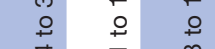

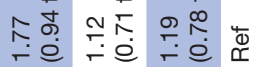

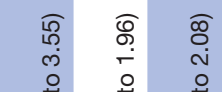

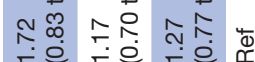

๕. लू \%ู

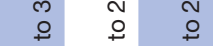

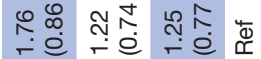$$
\text { 政 }
$$

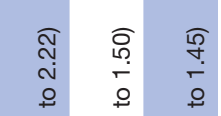

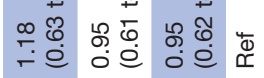

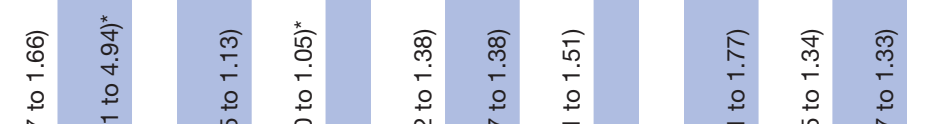

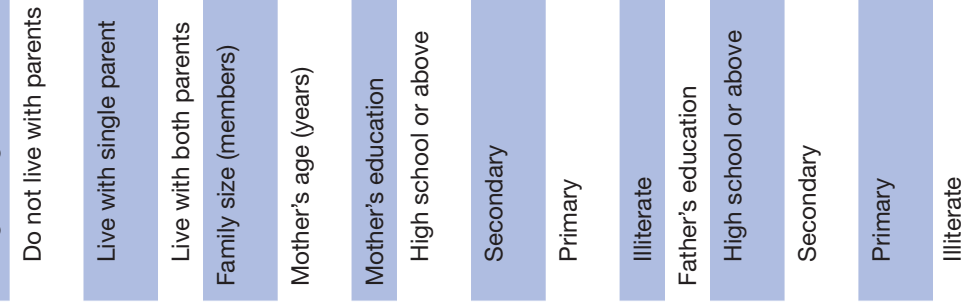




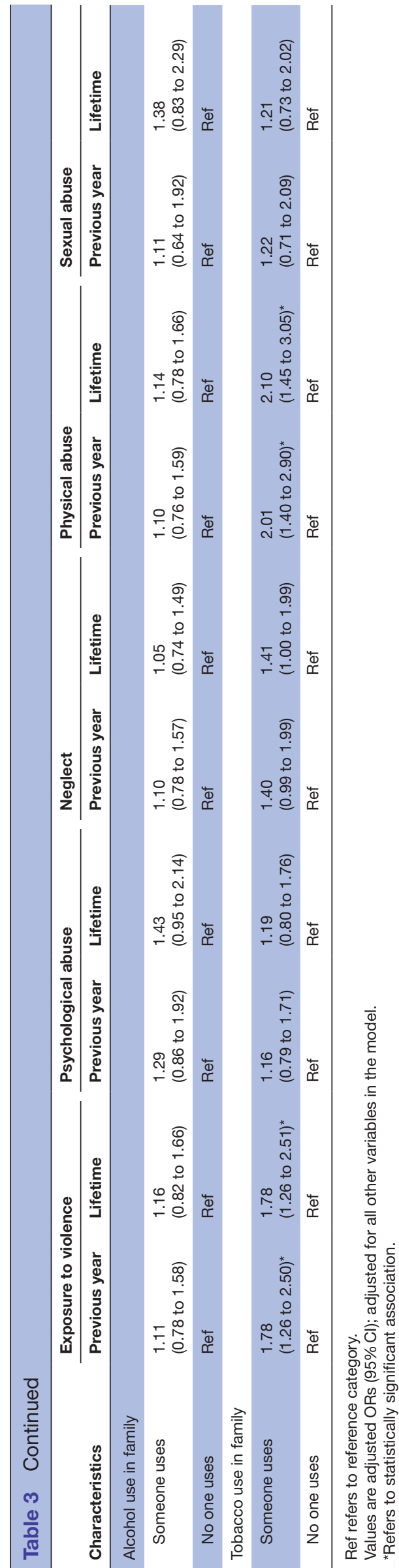

CONCLUSIONS

This comprehensive study among secondary students from public schools in Kathmandu suggests that a huge proportion of students have experienced abuse in the home. The most common form of abuse experienced by students was psychological abuse followed by physical abuse, exposure to violence, neglect and sexual abuse. Future studies need to focus on identifying the reasons for the high burden of abuse and its implications. Studies among children from other geographical areas and those in institutions other than public schools, including private schools, military schools and the general community, are needed to have a more robust understanding of the burden of child abuse in Nepal.

Acknowledgements The authors thank the school principals for their support during data collection. The authors also thank Tony V Pham, Duke University for his help with English editing, and Scott Halliday, Possible Health for his valuable comments on the manuscript.

Contributors DN conceived and designed this study. DN, PMB, SB and KT collected the data. DN and PMB analysed the data. DN, PMB, KT, SB and SR drafted the paper. DN and PMB finalised the paper. RPP supervised this study and contributed to drafting the paper. All authors read and approved the final paper.

Funding This research received no specific grant from any funding agency in the public, commercial or not-for-profit sectors.

Competing interests None declared.

Patient consent Not required.

Ethics approval Nepal Health Research Council (reference No. 197-2015).

Provenance and peer review Not commissioned; externally peer reviewed.

Data sharing statement The original questionnaire used in this study can be obtained for no charge upon request from the website of International Society for the Prevention of Child Abuse and Neglect (www.ispcan.org). The translated questionnaire and the data are available from the corresponding author upon reasonable request.

Open access This is an open access article distributed in accordance with the Creative Commons Attribution Non Commercial (CC BY-NC 4.0) license, which permits others to distribute, remix, adapt, build upon this work non-commercially, and license their derivative works on different terms, provided the original work is properly cited and the use is non-commercial. See: http://creativecommons.org/ licenses/by-nc/4.0/

(c) Article author(s) (or their employer(s) unless otherwise stated in the text of the article) 2018. All rights reserved. No commercial use is permitted unless otherwise expressly granted.

\section{REFERENCES}

1. Stoltenborgh M, Bakermans-Kranenburg MJ, Alink LRA, et al. The prevalence of child maltreatment across the globe: review of a series of meta-analyses. Child Abuse Review 2015;24:37-50.

2. Brown DS, Fang X, Florence CS. Medical costs attributable to child maltreatment: a systematic review of short- and long-term effects. Am J Prev Med 2011;41:627-35.

3. Norman RE, Byambaa M, De R, et al. The long-term health consequences of child physical abuse, emotional abuse, and neglect: a systematic review and meta-analysis. PLOS Med 2012;9:e1001349.

4. Leeb RT, Lewis T, Zolotor AJ. A review of physical and mental health consequences of child abuse and neglect and implications for practice. Am J Lifestyle Med 2011;5:454-68.

5. CPCS and VOC. The abuse of street children in Kathmandu. Kathmandu, Nepal: CPCS and VOC, 2008.

6. Kandel P, Kunwar R, Karki S, et al. Child maltreatment in Nepal: prevalence and associated factors. Public Health 2017;151:106-13.

7. CWIN and UNICEF. Violence against children in Nepal. Nepal: CWIN and UNICEF, 2005. 
8. Emery CR, Thapa S, Do MH, et al. Do family order and neighbor intervention against intimate partner violence protect children from abuse? Findings from Kathmandu. Child Abuse Negl 2015;41:170-81.

9. Global Initiative to End All Corporal Punishment of Children. Corporal punishment of children in Nepal. 2017 http://www.endcorporalp unishment.org/assets/pdfs/states-reports/Nepal.pdf (accessed 04 November 2017).

10. Berger LM. Income, family structure, and child maltreatment risk. Child Youth Serv Rev 2004;26:725-48.

11. Brown J, Cohen P, Johnson JG, et al. A longitudinal analysis of risk factors for child maltreatment: findings of a 17-year prospective study of officially recorded and self-reported child abuse and neglect. Child Abuse Negl 1998;22:1065-78.

12. Mathema KB. Crisis in education and future challenges for Nepal. European Bulletin of Himalayan Research 2007;31:46-66.

13. Neuman SB, Khan N, Dondolo T. When I Give, I Own: Building Literacy Through READ Community Libraries in Nepal. Read Teach 2008;61:513-22.

14. Zolotor AJ, Runyan DK, Dunne MP, et al. ISPCAN Child Abuse Screening Tool Children's Version (ICAST-C): instrument development and multi-national pilot testing. Child Abuse Negl 2009;33:833-41.

15. Gellner DN. Caste, ethnicity and inequality in Nepal. Econ Polit Wkly 2007;42:1823-8.

16. Barth J, Bermetz L, Heim E, et al. The current prevalence of child sexual abuse worldwide: a systematic review and meta-analysis. Int J Public Health 2013;58:469-83.

17. Turner HA, Finkelhor D, Ormrod R. Poly-victimization in a national sample of children and youth. Am J Prev Med 2010;38:323-30.

18. Chan KL. Victimization and poly-victimization among school-aged Chinese adolescents: prevalence and associations with health. Prev Med 2013;56:207-10.

19. Lätsch DC, Nett JC, Hümbelin O. Poly-victimization and its relationship with emotional and social adjustment in adolescence:
Evidence from a national survey in Switzerland. Psychol Violence 2017;7:1-11.

20. Finkelhor D, Shattuck A, Turner HA, et al. The lifetime prevalence of child sexual abuse and sexual assault assessed in late adolescence. $J$ Adolesc Health 2014;55:329-33.

21. Nanda P, Gautam A, Verma R, et al. Study on Gender, Masculinity and Son Preference in Nepal and Vietnam. New Delhi, India: International Center for Research on Women, 2012.

22. Akmatov MK. Child abuse in 28 developing and transitional countries--results from the Multiple Indicator Cluster Surveys. Int J Epidemiol 2011;40:219-27.

23. Stith SM, Liu T, Davies LC, et al. Risk factors in child maltreatment: a meta-analytic review of the literature. Aggress Violent Behav 2009;14:13-29.

24. Emery CR, Eremina T, Arenas C, et al. When Bigger is better: household size, abuse injuries, neglect, and family response in Novosibirsk, Russia. J Interpers Violence 2017.

25. Leung PW, Wong WC, Chen WQ, et al. Prevalence and determinants of child maltreatment among high school students in Southern China: a large scale school based survey. Child Adolesc Psychiatry Ment Health 2008;2:27.

26. Walsh C, MacMillan HL, Jamieson E. The relationship between parental substance abuse and child maltreatment: findings from the Ontario Health Supplement. Child Abuse Negl 2003;27:1409-25.

27. Central Bureau of Statistics. National Population and Housing Census 2011: social characteristics tables (Disability, Literacy Status and Educational Attainment). Kathmandu, Nepal: Central Bureau of Statistics, 2014.

28. Sofuoğlu Z, Sariyer G, Aydin F, et al. Child abuse and neglect among children who drop out of school: a study in Izmir, Turkey. Soc Work Public Health 2016;31:589-98.

29. Curtis T, Miller BC, Berry EH. Changes in reports and incidence of child abuse following natural disasters. Child Abuse Negl 2000;24:1151-62. 